\title{
Integrating Global Englishes in English for Real Life Course
}

\author{
Charisopon Inthapat ${ }^{*}$ Punwalai Kewara Denchai Prabjandee \\ Faculty of Education, Burapha University, Chonburi, Thailand \\ * E-mail of the corresponding author: charisopon@gmail.com
}

\begin{abstract}
This study investigated the effects of integrating Global Englishes in an English for Real Life course on learners' ability to use English and attitudes toward Global Englishes. Utilizing the research and development approach, Global Englishes activities were developed from the needs analysis and later integrated into a pre-existing English curriculum, English for Real Life. The participants were twenty learners at a vocational university in central Thailand. The analysis of interviews and ethnographic field notes yielded the findings that the learners were more open to language differences, and they developed a tolerance for ambiguity, which later increased their ability to use English with culturally diverse English users. They also reported having much more knowledge about Global Englishes than before learning. However, the learners still believe in standard English. Implications are also discussed.
\end{abstract}

Keywords: Global Englishes; Global Englishes Language Teaching; English for Real Life; curriculum innovation DOI: $10.7176 / \mathrm{JEP} / 13-5-03$

Publication date: February $28^{\text {th }} 2022$

\section{Background of the Study}

The spread of English as a global phenomenon has implications for English Language Teaching (ELT) (Rose and Galloway, 2019). It becomes evident that "the English language" and the demographic reality of English users outside of the classroom are changing dramatically, thus, it warrants the need to reconceptualize English and how it should be taught (Matsuda, 2019; McKay, 2018). First, English should be treated as pluricentric, in which it has multiple norms (Galloway and Numajiri, 2020). Second, the global spread of English makes it no longer relevant to associate it exclusively with native-speaking nations, rather, English should be regarded as a paradigm with global ownership (Galloway and Rose, 2015). Thus, in terms of ELT, learners should become aware of the extant English varieties (Matsuda, 2003). They should also treat diverse Englishes with respect and nurture positive attitudes toward Englishes (Sung, 2015b). Finally, learners should be able to communicate in English with people of various nationalities and in cross-cultural communication (Galloway and Numajiri, 2020).

To correspond to these changes, many proposals have been suggested to be implemented in the classroom to prepare learners to communicate with culturally diverse English users such as English as a Lingua Franca (ELF)aware teaching (Sifakis, 2019), Teaching English as an International Language (Marlina, 2018; Matsuda, 2019; McKay, 2018), World Englishes-informed ELT (D’Angelo, 2012; Sadeghpour and Sharifian, 2019), a postnormative approach (Dewey, 2012), Teaching English for Glocalised Communication (TEGCOM) (Lin et al., 2002), and Global Englishes for Language Teaching (GELT) (Rose and Galloway, 2019). Although these proposals use different terms, they share a fundamental desire to shift away from using Native English Speakers (NES) as a single benchmark to measure competence to evaluate diverse Englishes. This study sits on the shoulders of GELT since it is an emerging field that receives tremendous interest from many researchers (Fang and Ren, 2018; Galloway and Rose, 2018; Rosenhan and Galloway, 2019; Sung, 2015b). The current state of research on GELT has called for the need to implement it in the classroom (Galloway and Rose, 2018; Sung, 2015a). Thus, more research should be conducted to understand how GELT could be implemented in classroom contexts. This paper attempts to contribute to this line of inquiry by exploring the effects of integrating GELT in the English for Real Life course in the university context of Thailand.

\section{Literature Review}

\subsection{Global Englishes}

Global Englishes is an umbrella term, consolidating the implications from related paradigms of World Englishes (WE), ELF, English as an International Language (EIL), and translanguaging (Galloway and Rose, 2018; Rose and Galloway, 2019). First, the field of WE attempts to codify linguistic features of localized English varieties in the outer circle based on the three concentric circles by Braj Kachru (Galloway and Rose, 2014). By acknowledging the existence of WE, the proponents of the paradigm of Global Englishes argue that other forms of English varieties are legitimate beyond those considered standard (Rose et al., 2020). Second, the field of ELF explores the interaction of NNES from the expanding circle, reflecting how English is used in the global context (Rose et al., 2019). Drawing the implications from ELF, Global Englishes acknowledge the complexity of interaction between English users nowadays, in which they bring multilingual repertoires, trans-languaging practices, and an established identity with them to communicate with each other (Rose and Galloway, 2019). Third, 
the focus of EIL is to explore the implications of the status of English as an international phenomenon for society and language education (Rose and Galloway, 2019).

Taken together, Global Englishes is an ELT paradigm aimed at preparing learners to communicate with English users from diverse sociocultural backgrounds. It acknowledges the pluricentric nature of English (Galloway and Numajiri, 2020). Global Englishes also argues for claiming English as global ownership since it is used globally (Saeki, 2015; Widdowson, 1994). To implement Global Englishes in the classroom, Rose and Galloway (2019) developed the GELT framework. From the GELT perspective, the goal for learning English is not to achieve native-like proficiency, rather, the goal lies in becoming a multi-competent English user (Rose and Galloway, 2019). Also, the target interlocutors are all English users (NES or NNES), thus making it difficult to predict who the interlocutors are. Additionally, because English is used globally, it should be treated as global ownership (Higgins, 2003). The target culture to be taught is fluid (Baker, 2018), and other cultures and English users' first languages are to be seen as a resource, not a hindrance for learning. Furthermore, since English has diverse, multiple, and flexible norms, learning materials should be drawn from the global use of English from diverse communities. Moreover, assessment from this perspective should be for measuring communicative competence, not simple accuracy based on the standard norm (Rose and Galloway, 2019).

\subsection{Global Englishes in the Classroom}

Several researchers have implemented Global Englishes in the classroom (Fang and Ren, 2018; Galloway and Rose, 2018; Lu and Buripakdi, 2020; Rose and Galloway, 2017; Sung, 2015b; Tardy et al., 2021). It is observed that these studies used a content-based approach when implementing Global Englishes. To elaborate, these researchers developed a new Global Englishes course and included several themes constructively aligned to help learners understand the concept of Global Englishes. The outcomes of the course were often investigated in terms of attitudes change toward Global Englishes or their own English. For example, Fang and Ren (2018) designed a new English course, English as a World Language, for university learners in China to introduce the global spread of English use in various territories, language ideologies and attitudes related to ELT, and language rights and discrimination. It was found that the course helped learners who "developed an awareness of the diversity of English and did not feel ashamed of their own English" (Fang and Ren, 2018, p. 388).

Even though promising evidence was reported in prior research, it is observed that using the content-based approach (developing a new Global Englishes course) requires teachers to relinquish their existing curricula and adopt new content to be taught in the classroom. Such adoption may not be practical in many contexts since the opportunities to develop a new English course may be confined by extant policy for curriculum structure. Thus, the findings in those previous studies may have limited ecological validity. As a result, it is important to search for a new approach to implement GELT in the classroom. An extensive literature review suggests that prior research employed an integration approach, in which GELT was integrated into existing curricula (Siqueira, 2020; Sung, 2015b). For example, Sung (2015b) integrated Global Englishes components into a university English course in Hong Kong and pointed out overwhelmingly positive course outcomes. It was reported that "all of the students appreciated the discussions concerning the spread of English, different varieties of English and ELF communication" (Sung, 2015b, p. 44). Also, Siqueira (2020) integrated ELF into an EFL curriculum, where the dialog between the two approaches can emerge in the current ELT to help learners that their future lives of English use means using ELF. Through the decolonizing lens of language use, Siqueria (2020) demonstrated examples of integrating ELF.

Finally, it is also clear that the outcomes of Global Englishes courses in previous studies were explored purely in terms of attitudinal changes. Other important variables such as the ability to use English were excluded from the analysis. Since the focus of GELT is to prepare learners to communicate with linguistically diverse English users (Rose and Galloway, 2019), it is legitimate to explore how learners develop their English ability after taking an English course, integrated with Global Englishes. This sphere of research significantly contributes to the theoretical discussion of GELT implementation. This study attempts to find answers to the following research questions:

1. To what extent does integrating Global Englishes in the English for Real Life course enhance learners' ability to use English?

2. To what extent does integrating Global Englishes in the English for Real Life course influence learners' attitudes toward Global Englishes?

\section{The Present Study}

\subsection{Context of the Study}

This study was conducted at a university in the central part of Thailand, which offers a compulsory English course for all undergraduate students, called English for Real Life. Initially, the course aimed to develop learners' English language skills (listening, speaking, reading, and writing), knowledge of vocabulary, and basic sentence English structures to be used in real life. The university offers work-based education, dividing an academic year into four 
intensive semesters, providing opportunities for learners to study and work at the university's network companies. To elaborate, the learners learn at the university for three months, and they enter the field to work for three months at the university's network companies. The learners are divided into Block courses (Block A and Block B). In the first semester (semester 1.1), the Block-A learners learn at the university, and the Block-B learners work. Then, in the second semester (semester 1.2), the Block-A learners work and the Block-B learners study. After that, they take turns again in semesters 2.1 and 2.2. The network companies in this study refer to convenience stores, located in tourist attractions, where the learners have opportunities to use English to provide services for foreign customers. This work-based context allows us to witness at first hand how learners use English before they enroll in the English for Real Life course (semester 1.1) and after taking the course (semester 2.2). These data were uniquely from prior research, which focused solely on self-reported data.

\subsection{Research Design}

The objective of this study was to develop Global Englishes activities and integrate them into an existing English curriculum, an English for Real Life course. To achieve the objective, a process-oriented approach was used to develop Global Englishes activities. Thus, a Research and Development (R \& D) methodology was used to systematically design Global Englishes activities, field-test them, and refine them until they reached the quality required (Gall et al., 2007). In this study, the R \& D approach consists of three phases as follows: 1) a needs analysis, 2) developing the required Global Englishes activities, and 3) implementing Global Englishes activities.

Phase 1: Needs Analysis

To avoid imposing Global Englishes on learners, we decided to conduct a needs analysis to determine whether the learners really need to learn about Global Englishes. Utilizing the critical needs analysis (Benesch, 1996), an ethnographic strategy and interviews were used to investigate learners' needs in terms of necessities, lacks, and wants as characterized by Nation and Macalister (2010), and to explore how social position and unequal power were manifested in their needs (Benesch, 1996). First, the ethnographic strategy was employed to observe how the Block-A learners $(\mathrm{n}=20)$ used English at the network companies. Field notes and conversations were also collected. Second, semi-structured interviews were also conducted. Some examples of the questions were: Have you communicated with foreigners at work? Who are they? What was it like when you communicated with those English users? Have you had any problems communicating with those English users? If you had, what did you do? Lastly, five entrepreneurs who supervised the learners were also interviewed about learners' performance at work to triangulate the results from the learners' perspectives. The trustworthiness of the analysis was achieved in terms of data triangulation from the learners' perspective and entrepreneurs' perspective.

The data revealed that the learners lacked the ability to communicate with culturally diverse English users, had only limited ability to use communication strategies to carry on a conversation, possessed insufficient vocabulary and grammar knowledge, and held an accent bias against NNES. These responses indicated the necessity to prepare learners to understand Global Englishes since they had narrow views of English use outside of the classroom. Additionally, social position and unequal power were manifested in the learners' needs as they described their inferior positions and lacked confidence about their grammar and vocabulary knowledge when communicating with diverse English users. Based on these needs, it was evident that the learners still needed vocabulary and grammar knowledge to be able to use English making it no longer relevant to develop a new Global Englishes course in isolation and teach it as content. Therefore, Global Englishes should be integrated into the existing curriculum.

Phase 2: Developing Global Englishes Activities

To develop Global Englishes activities, we decided to examine previous studies to look for some examples (Galloway and Rose, 2018; Rosenhan and Galloway, 2019; Sung, 2015b). The design of activities was based on the GELT framework (Rose and Galloway, 2019). To integrate the Global Englishes activities, the first author looked through the main textbook (World English 2 by Johannsen and Chase, 2015) and examined possible opportunities to integrate Global Englishes activities. For example, in the topic of "Food from the earth," examples of food in the textbook are only from Western cultures. As a result, attempts were made to include food from Eastern cultures, and prompted the learners to compare different kinds of food and how such understanding of different food is beneficial for the learners when communicating with diverse English users. Another example of integration was about bringing more varieties of English into the classroom to illustrate that the examples of interaction in the textbooks do not always correspond to the sociolinguistic reality of English users.

By looking through opportunities to integrate Global Englishes, we developed 10 Global Englishes activities: 1) greetings from various cultures, 2) food from around the world, 3) categorization of English users, 4) local cultures, 5) role models of English users, 6) WE, 7) listening to various accented Englishes, 8) a shift to Global Englishes, 8) guess where they are from, and 10) a Global Englishes presentation. In week 1, the goal was icebreaking about cultural differences in greeting. To encourage the learners to accept various varieties of English, the lesson of week 3 (categorization of English users), week 5 (role models of English users), and week 6 (WE) were offered to the learners by using the three concentric circles developed by Kachru (1992). The other six lessons 
for weeks 2, 4, 7, 8, 9 and 10 exposed the learners to various cultures of English usage. Additionally, vocabulary and grammar lessons remained being instructed explicitly throughout the units. The activities were field-tested with the Block-B students (semester o1.2).

Phase 3: Implementing Global Englishes Activities

In this phase, the goal was to explore the effects of the Global Englishes activities on learners' ability to use English and attitudes toward Global Englishes. The first author was the instructor on the English for Real Life course. The Global Englishes activities were implemented with 20 learners from Block A (semester 2.1). Their ages ranged from 18-20 years old. Ten learners were male, and ten were female. The duration of instruction integrated with Global Englishes activities was 10 weeks. To determine the effects, the learners' ability to use English was assessed qualitatively by observing how they used English at work (semester 2.2). The first author conducted observation naturally as a non-participant observer. Field notes were used to document learners' ability to use English at work and compared with semester 1.1 in the needs analysis phase. It took 15 hours of observation until the data was adjudged saturated. Second, attitudes toward Global Englishes were assessed by using the interviews before and after taking the course. The data were analyzed by using the coding method to compare learners' ability to use English and attitudes toward Global Englishes before and after receiving the instruction with Global Englishes activities. It should be noted that the effects of this phase were not evaluated in terms of a supposed causal relationship given the limitations of qualitative research. Rather, the goal of the analysis was to provide a descriptive exploration of how Global Englishes activities impacted the learners.

\subsection{Ethical Considerations}

Before collecting the data, this study was approved by the Institutional Review Board. The learners, when approached by the second author who did not exercise undue influence on learners' decision to participate in this research, signed the consent form to grant permission to collect the data from them. They were aware that they could drop out of the research at any time without negative consequences to their learning. When reporting the data, they understood that pseudonyms were used to protect their confidentiality.

\section{Findings \\ 4.1 Increased Ability to Comprehend Diverse English Users}

Before taking the course, the learners were placed to work at the network companies (semester 1.1), where they had opportunities to interact with diverse English users, both NES and NNES. In semester 1.1, it was clear that the learners $(n=16$ out of 20) struggled to communicate with culturally diverse English users as they reported in the interview that they did not understand when some NNES pronounced accented English words. However, after taking the English for Real Life course, it was found that the learners initially developed an openness to the language difference, tolerance to ambiguity, and flexible views of English use. Later, these initial dispositions helped increase their ability to comprehend diverse English users. To elaborate, the data from observation indicated that the learners $(n=20)$ were more open to English use beyond preconceived standards and tolerance to continue a conversation with diverse English users. They also developed communication strategies to engage in conversation, to create rapport with their interlocutors, and to make themselves understood. For example, in an incident, after a learner (Student-7) had worked for three weeks (semester 2.2), the first author observed the learner trying to make a connection with an English user from China. The learner smiled at the Chinese and greeted "Nihao!" before engaging in conversation. After that, the conversation went smoothly and achieved communicative purposes.

Consistently, upon asking what they had learned after taking the English for Real Life course, the interview data illustrated that the learners $(n=20)$ developed strategies to tolerate language differences, ambiguity, and communication strategies to engage in conversation with diverse English users. To elaborate, in semester 1.1, when the learners did not understand what the foreigners said, they often just froze and stayed silent. Many of them $(n=14)$ walked away from the interaction. However, after taking the course, the learners were more patient with ambiguity, and they adopted several communication strategies to carry on a conversation as illustrated in the following quotes.

I am more familiar with Chinese, Filipino, and Indian people than before. When I listened to their English, I understood (more) even though they don't say the whole sentence. For example, a foreigner said to me "I need same same.," I understand immediately that he needed Americano coffee (Student-1)

After the course, I felt that I could guess what non-native English speakers wanted to say even though their accents were not like native speakers. If I did not understand what they said, I asked them to wait for me or asked foreigners to speak again so that I know what they wanted. The course also taught me to listen to only key words when I communicated with non-native speakers. I did that and it worked. I tried to explain myself, and I understood what the foreigners need (Student-3)

Moreover, since the course helped them become more tolerant of accented Englishes, it was found that the learners gradually developed the ability to communicate with culturally diverse English users. This development 
was attributed to the fact that they were more open to language differences, so when they interacted with frequent customers at the convenience stores, they were able to. For example, a learner reported that when a NNES said "I need sky sky" it meant they needed a cigarette of the "Sky Blue" brand. Another example was an Indian speaker who came to the store in the morning and said, "Oh breakfast." The learner knew that the Indian person wanted to buy a sandwich and cigarettes. The following quotes from the interview illustrated how learners developed their ability to use English with diverse English users.

From the first week after I learned English for real life course, I only knew that English has varieties, but I could communicate with non-native English speakers, just a little bit. Until week 3 or 4, I felt that I could communicate with both native and non-native English speakers of English. I am more confident to talk to them (Student-2).

I understand various accents (better) than (when) I worked in the previous time because I feel that I can communicate more effectively than the first week when I started the internship. I can listen to keywords from the foreigners' speech. Then, I use the words which I know about those products even though my accent is Thai to communicate with them (Student-7).

\subsection{Perpetual Attitudes toward Native English Speakers}

Even though it was found that the learners were more open to language differences, and they developed tolerance to ambiguity after taking the course, it was surprising to learn that most learners' attitudes toward Global Englishes remained unchanged. To elaborate, before taking the course, the learners $(n=20)$ reported a strong preference toward "Standard English." For example, one learner reported in the interview that "British and American English are the only acceptable English since they are standard" (Student-11). However, unlike prior research which revealed that the learners changed attitudes toward Global Englishes, this study found that most of the learners (n $=16$ ) did not change their attitudes toward Global Englishes after taking the English for Real Life course. The data from the interview indicated that most learners $(n=16)$ continued to perceive NES as a better role model for language learning than NNES. Upon asking whether what they think about English varieties after the learners had completed the course, the following quotes illustrated how the learners continued perceiving NNES as inferior to NES.

In my view, when I communicated with non-native English speakers at work, they speak unclear English. I think they always pronounce (with the) wrong accent, and their accents are difficult to understand. I know that we should accept the differences, but I cannot help thinking that if they speak with the correct accent, maybe I can understand more (Student-11).

I don't mean that I only accepted native speakers' accent and I accept non-native speakers as well. However, I am not sure that when non-native speakers speak English, the native speakers understand or not. Moreover, if I accept non-native speakers and use English like them such as the Singaporean accent, (will) native speakers such (as) an American person understands me or not? (Student-19).

These quotes indicated that the learners continued holding negative attitudes toward NES even though they had completed the English for Real Life course, integrated with Global Englishes activities. It was clear that they perceived NNES accents as deviant from the standard, and therefore, not acceptable. However, four learners expressed the tendency to change their attitudes toward Global Englishes as they understood that "the English language" is now changing since it is influenced by users' mother tongues.

I know that English is interfered by the non-native speakers' mother tongue. After I was trained with the activities in the course, I understand that English can be changed when it is spoken in various countries (Student-10).

I changed my idea and I accept more varieties of English than before. I understand that English is interfered by local language. If we communicate and (can) understand each other, it is successful communication (Student-17).

It should be noted that it was challenging to identify possible reasons why the attitudinal differences between the majority $(n=16)$ and the minority $(n=4)$ of responses existed. In trying to analyze the differences in terms of learner characteristics, the data were not adequate to determine why these differences occurred.

\subsection{Greater Knowledge of Global Englishes}

Apart from investigating learners' ability to use English and attitudes toward Global Englishes, this study also yielded the unexpected outcome that the learners developed greater knowledge of Global Englishes after taking the English for Real Life course. Before taking the course, out of 20 learners, only three learners appeared to understand that English has varieties. However, after taking the course, all students $(\mathrm{n}=20)$ reported in the interview that they had increased knowledge of Global Englishes as illustrated in the quotes below.

I understand that English has varieties, and I know that English is the language that the people around the world use for communication. So, people in every country should be able to communicate in English. Moreover, the use of English is interfered by local language, and it is included the culture of those countries 
when English is used in other places (Student-3).

After I learned the activities from the English for real life course, I understand English is a global language and it is differently used by various people around the world. Moreover, when the people use English, they include their culture in the language (Student-5)

I know that English is the language that the people around the world use for communication. I have just known that English is used in the inner, outer, and expanding circle country (Student-7)

Based on the responses above, it was clear that the learners were aware of the pluricentricity of English, which was influenced by the user's mother tongue and local culture. They also became more aware that English has varieties, in which they used Kachru's model of WE to describe those varieties. Even though these understandings are incomplete, it was clear that the learners started to develop the knowledge of Global Englishes, which could be a predetermined condition to be open to learning about Global Englishes.

\section{Discussion}

This study attempted to explore the effects of integrating Global Englishes activities into an English for Real Life course on learners' ability to use English and attitudes toward Global Englishes. Utilizing the R \& D methodology, ten Global Englishes activities were developed, field-tested until they reached the expected quality, and implemented with 20 learners enrolled in the English for Real Life course at the vocational university in central Thailand. The effects of Global Englishes activities were documented qualitatively by using the interviews and an ethnographic strategy to observe how the learners used English at the university's network companies. It was revealed that the learners develop openness to language differences and tolerance of ambiguity, which later increased their ability to comprehend diverse English users. However, their attitudes toward Global Englishes, in the main, remained constant after taking the course. These findings provided empirical evidence to indicate the outcomes of the integration approach to implement Global Englishes in the classroom.

The integration of Global Englishes into an existing curriculum found that the learners developed an openness to language differences and tolerance of ambiguity. This development could be characterized as translingual dispositions (Lee and Jenks, 2016; Tupas, 2020). According to Lee and Jenks (2016), a translingual disposition is "general openness to plurality and difference in the ways people use language, are central for all users of English in a globalized society, and the fostering of such proclivities is an imperative to the contemporary composition classroom" (p. 317). The potential to develop a translingual disposition after integrating Global Englishes in the existing curriculum is a unique finding in the implementation of Global Englishes in the classroom. Subsequently, the translingual disposition supported the development of the ability to use English in real life since it reminded the students to be open to language differences and to take risks when communicating with culturally diverse English users. In addition, it was also revealed that the learners developed greater knowledge of Global Englishes. The findings were consistent with previous studies. Even though this study did not develop a new Global Englishes course to teach it as content, it was revealed that the learners also benefited from the integration approach. Thus, it could be concluded that both a content-based and integration approach helped the learners develop an understanding of Global Englishes.

However, the findings in this study revealed that the learners still held persistent attitudes toward NNES as they reported a strong preference toward standard English. The findings were not consistent with a prior search that employed a content-based approach by developing a new Global Englishes course (Fang and Ren, 2018; Galloway and Numajiri, 2020; Galloway and Rose, 2018). The differences between the two approaches might be attributed to the amount of explicit discussion of language use in the global context. To elaborate, in the contentbased approach, time was spent extensively to discuss the global spread of English in various contexts, language ideologies and attitudes toward English, and changing characteristics of the English language. In contrast, the integration approach spared some time to teach vocabulary and grammar. This finding pointed out the challenges in trying to change learners' attitudes toward Global Englishes when explicit instruction was not extensively employed.

It was clear that the outcomes of implementing Global Englishes in the classroom by using the two approaches (content-based and integration) are different. Therefore, it is up to the teachers to choose which approach is more practical to their contexts. If the teachers do not have opportunities to develop a new Global Englishes course, integrating Global Englishes into an existing curriculum can be also beneficial to the learners. The interpretation of this study should be cautious due to the limitations of qualitative exploration that does not allow for causal relationship generalization. Future research can employ a more robust research design with a control group to assess the causal effects of integrating Global Englishes in the classroom.

\section{Conclusion}

This study provides a theoretical contribution to the discussion about Global Englishes implementation. The outcomes of integrating Global Englishes into existing curricula are evident: learners developed a translingual disposition, which is required to develop the ability to use English with culturally diverse English users and 
increased knowledge of Global Englishes. However, student attitudes toward Global Englishes, in the main, remained unchanged after taking the course. These positive outcomes might be appealing for teachers to implement Global Englishes in the classroom. We would like to call for more research exploring the effectiveness of Global Englishes implementation. It is hoped that more research will add to the momentum of a paradigm shift in ELT.

\section{References}

Baker W (2018) The cultures of English as a lingua franca. TESOL Quarterly 43(4): 567-592.

Benesch S (1996) Needs analysis and curriculum development in EAP: An example of a critical approach TESOL Quarterly 30(4): 723-738.

D'Angelo J (2012) WE-informed EIL curriculum at Chukyo: Towards a functional, educated, multilintual outcomes. In: Matsuda A (eds) Principles and practices of teaching English as an international language. Bristol: Multilingual Matters, pp.138-157.

Dewey M (2012) Toward a post-normative approach: learning and pedagogy of ELF. Journal of English as a Lingua Franca, 1(1): 141-170.

Fang F and Ren W (2018) Developing students' awareness of global Englishes. ELT Journal, 72(4): 384-394.

Gall MD, Gall JP and Borg WR (2002) Educational Research. Boston, MA: Pearson Education.

Galloway N and Numajiri T (2020) Global Englishes language teaching: Bottom-up curriculum implementation. TESOL Quarterly 54(1): 118-145.

Galloway N and Rose H (2014) Using listening journals to raise awareness of global Englishes in ELT. ELT Journal 68(4): 386-396.

Galloway N and Rose H (2018) Incorporating Global Englishes into the ELT classroom. ELT Journal 72(1): 314.

Higgins C (2003) "Ownership" of English in the outer circle: An alternative to the NS-NNS dichotomy. TESOL Quarterly 37(4): 615-644.

Lee JW and Jenks C (2016) Doing translingual dispositions. College Composition and Communication 68(2): $317-$ 344.

Lin A, Wang W, Akamatsu N and Riazi AM (2002) Appropriating English, expanding identities, and re-visioning the field: From TESOL to teaching English for glocalised communication (TEGCOM). Journal of Language, Identity, and Education 1(4): 295-316.

Lu H and Buripakdi A (2020) Effects of global englishes-informed pedagogy in raising Chinese university students' global englishes awareness. PASAA 60: 97-133.

Marlina R (2018) Revisiting the pedagogy of English as an International Language. RELC Journal 49(1): 3-8.

Matsuda A (2003) Incorporating World Englishes in teaching English as an international language. TESOL Quarterly 37(4): 719.

Matsuda A (2019) World Englishes in English language teaching: Kachru's six fallacies and the TEIL paradigm. World Englishes 38(1-2): 144-154.

McKay SL (2018) English as an international language: What it is and whar it means for pedagogy. RELC Journal 49(1): 9-23.

Rose H and Galloway N (2017) Debating standard language kdeology in the classroom: Using the 'Speak Good English Movement' to raise awareness of Global Englishes. RELC Journal 48(3): 294-301.

Rose H and Galloway N (2019) Global Englishes for language teaching. Cambrigde UK: Cambridge University Press.

Rosenhan C and Galloway N (2019) Creativity, self-reflection and subversion: Poetry writing for Global Englishes awareness raising. System 84: 1-13.

Rose, H., Syrbe, Montakantiwong, \& Funada (2020). Global TESOL for the 21st century teaching English in a changing world. Bristol: Multilingual Matters.

Sadeghpour M and Sharifian F (2019) World Englishes in English language teaching. World Englishes 38(1-2): $245-258$.

Saeki T (2015) Exploring the development of ownership of English through the voice of Japanese EIL users. Asian Englishes 17(1): 43-58.

Sifakis N (2019) ELF awareness in english language teaching: Principles and processes. Applied Linguistics 40(2): $288-306$.

Siqueira S (2020) ELF with EFL: what is still needed for this integration to happen? ELT Journal 74(4): 377-386.

Sung CCM (2015a) Exposing learners to global englishes in ELT: Some suggestions. ELT Journal 69(2): 198201.

Sung CCM (2015b) Implementing a Global Englishes component in a university English course in Hong Kong. English Today 31(4): 42-49.

Tardy CM, Reed K, Slinkard JR and LaMance R (2021) Exploring Global Englishes content and language variation in an academic writing course. TESOL Journal 12(1): 1-11. 
Tupas R (2020) Fostering translingual dispositions against Unequal Englishes. English in Education 53(3): 1-17. Widdowson HG (1994) The ownership of English. TESOL Quarterly 28(2): 377. 